Doing FAIR (software)

\title{
in Environmental and Life Sciences
}

Wageningen, 12-12-2018 


\section{Acknowledgement : team at Netherlands eScience Center}

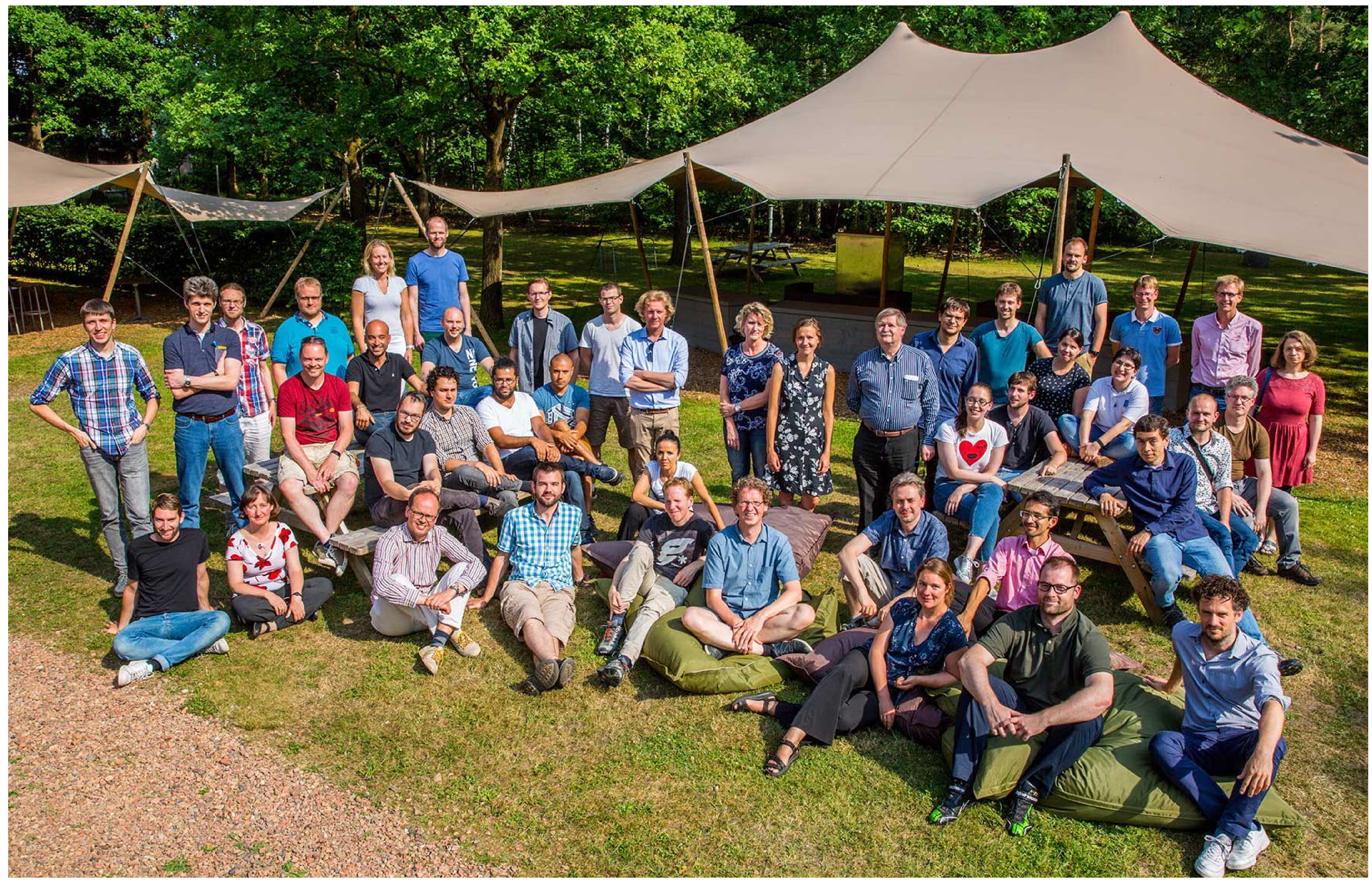




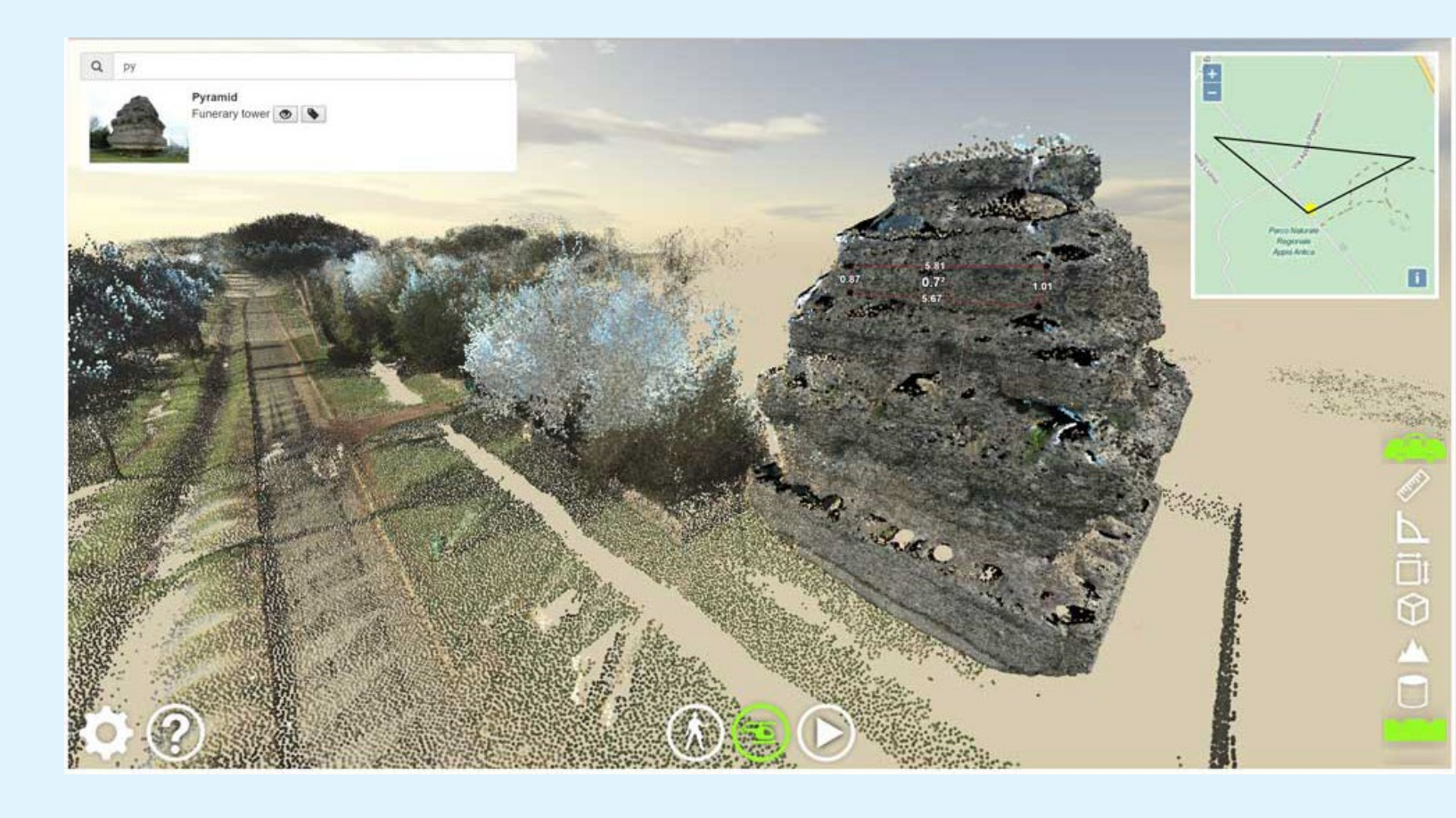

\section{$100+$ projects}

Humanities

\& Social Sciences

incl. SMART cities, text analysis, creative technologies

\section{Sustainability} \& Environment

incl. climate, ecology, energy, logistics, water management

\section{Physics}

\& Beyond

incl. astronomy, high-energy physics, advanced materials

\section{Life Sciences \\ \& eHealth}

incl. bio-imaging, next generation sequencing, molecules
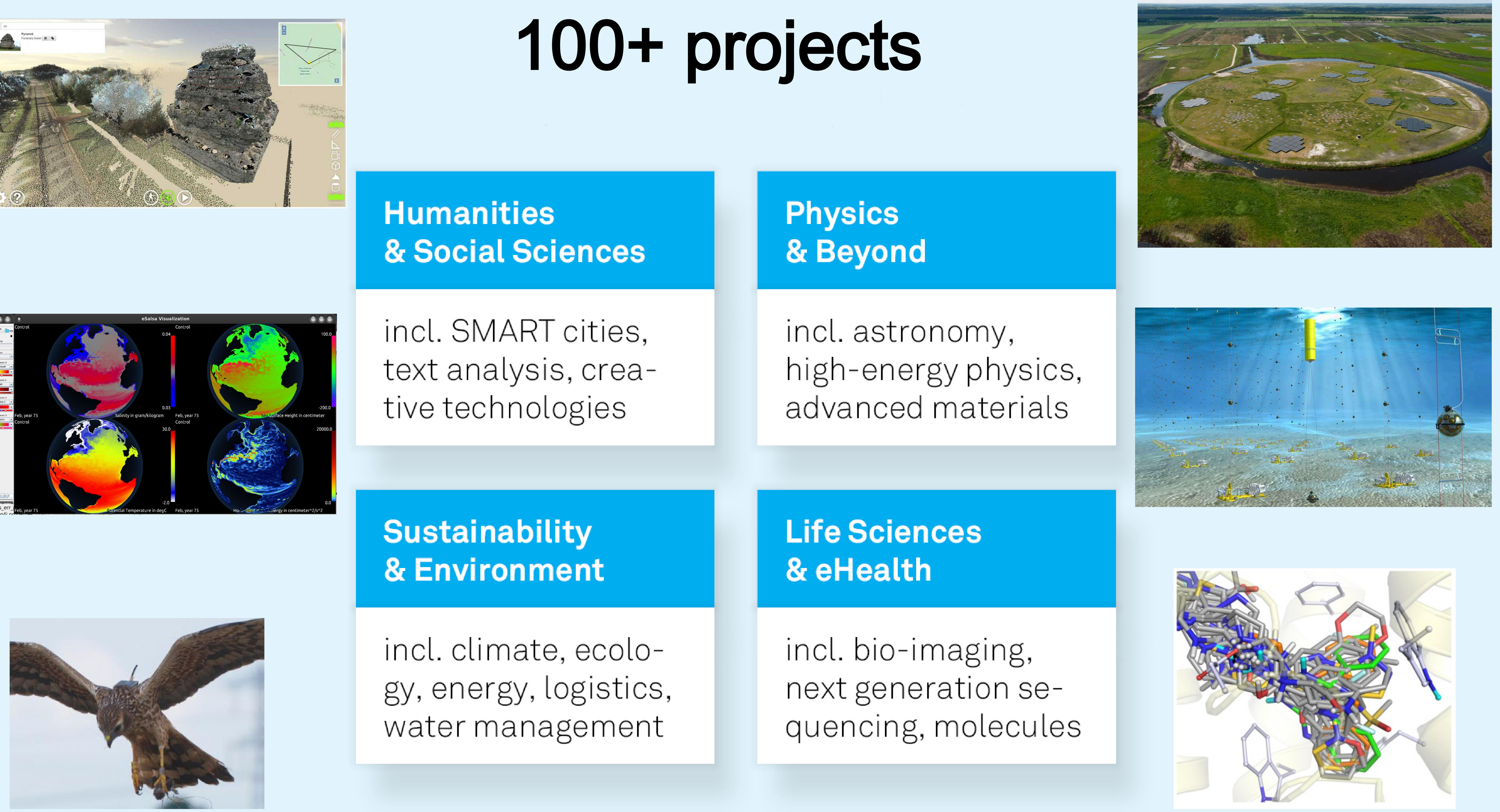


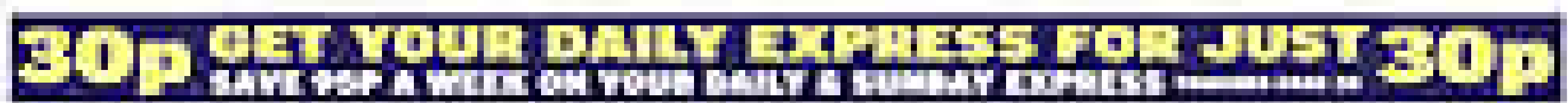
DAILY EXPRESS

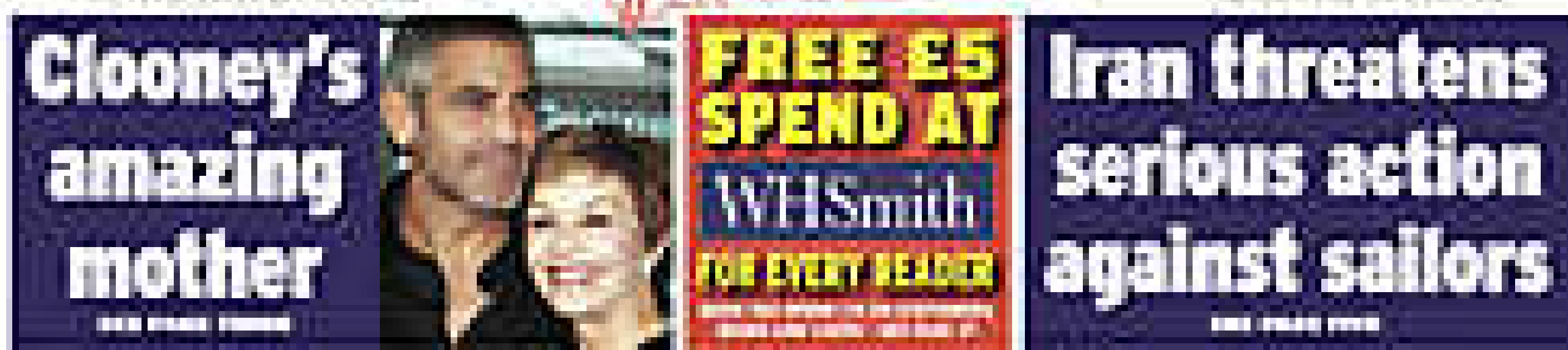
THE BIG CLIMATE CHANGE 'FRAUD'

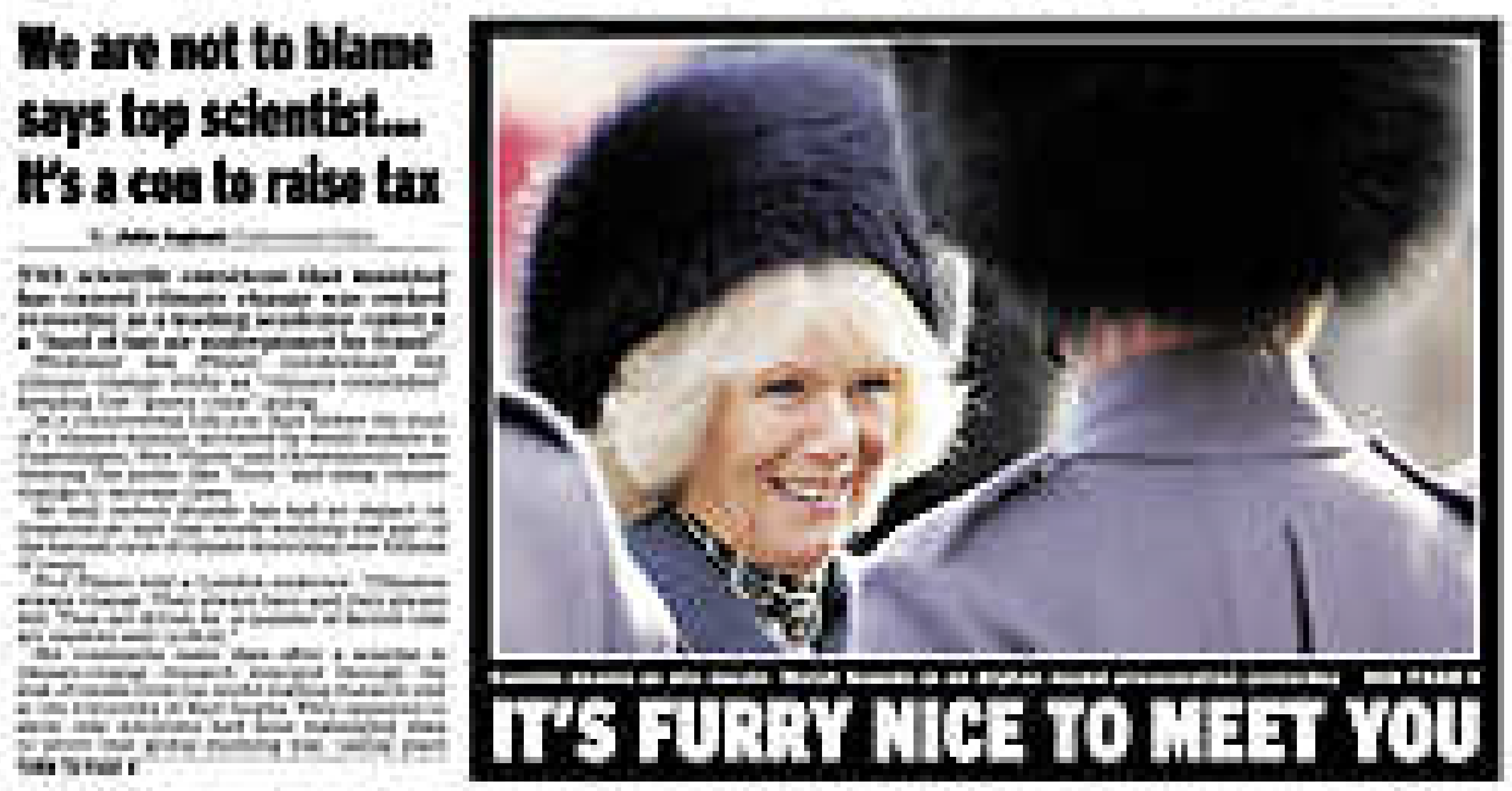


- In the context of the sharing of data and methodologies, .... Professor XX's actions were in line with common practice in the climate science community.

- It is not standard practice in climate science to publish the raw data and the computer code in academic papers. However, climate science is a matter of great importance and the quality of the science should be irreproachable. We therefore consider that climate scientists should take steps to make available all the data that support their work (including raw data) and full methodological workings (including the computer codes).

House of Commons

Science and Technology

Committee

The disclosure of climate data from the Climatic Research Unit at the University of East Anglia

Eighth Report of Session 2009-10

Report, together with formal minutes 


\section{IS THERE A REPRODUCIBILITY CRISIS?}

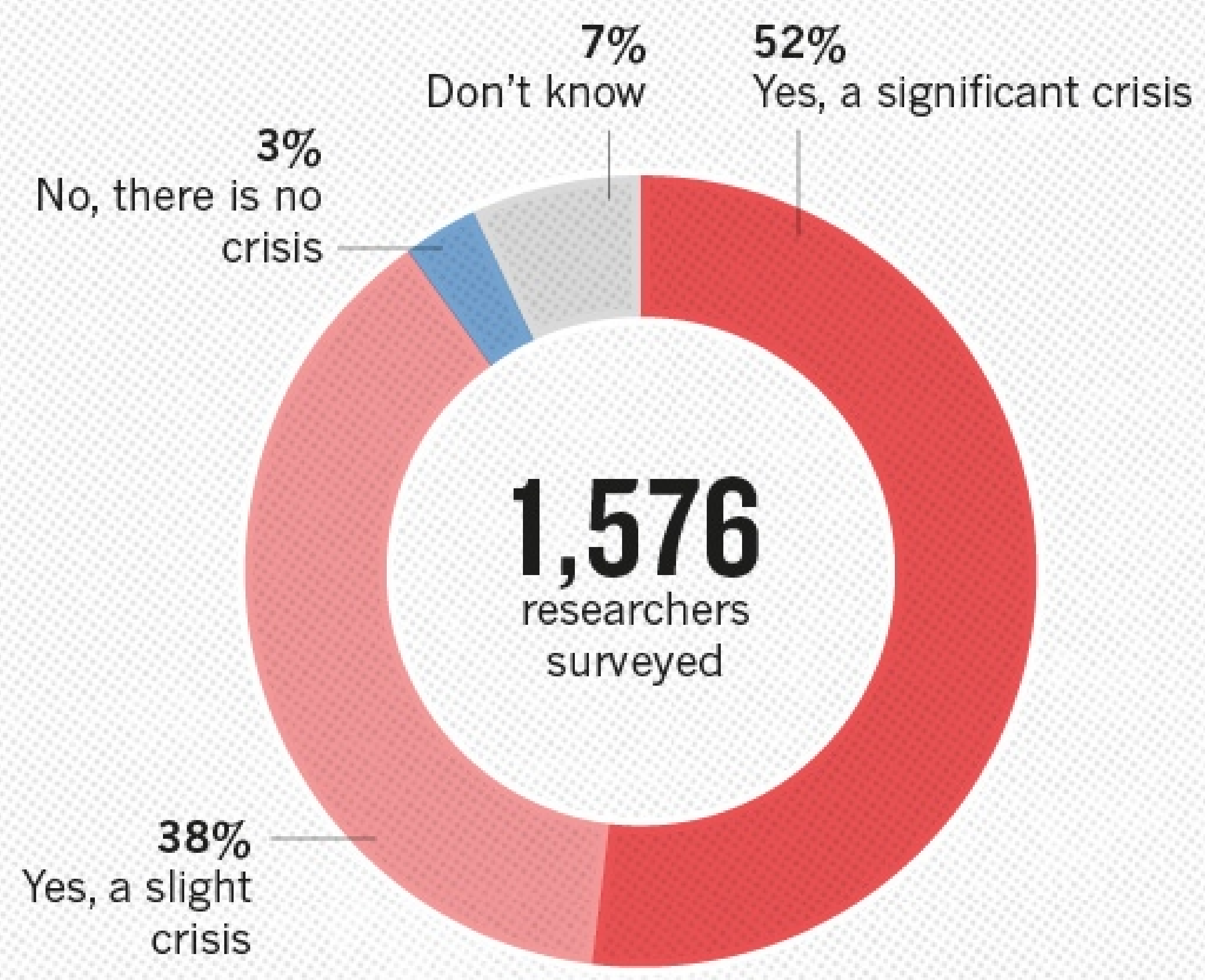



Open Science is about extending the principles of openness to the whole research cycle, fostering sharing and collaboration as early as possible thus entailing a systemic change to the way science and research is done

FAIR data principles and FAIR software principles contribute to open science 


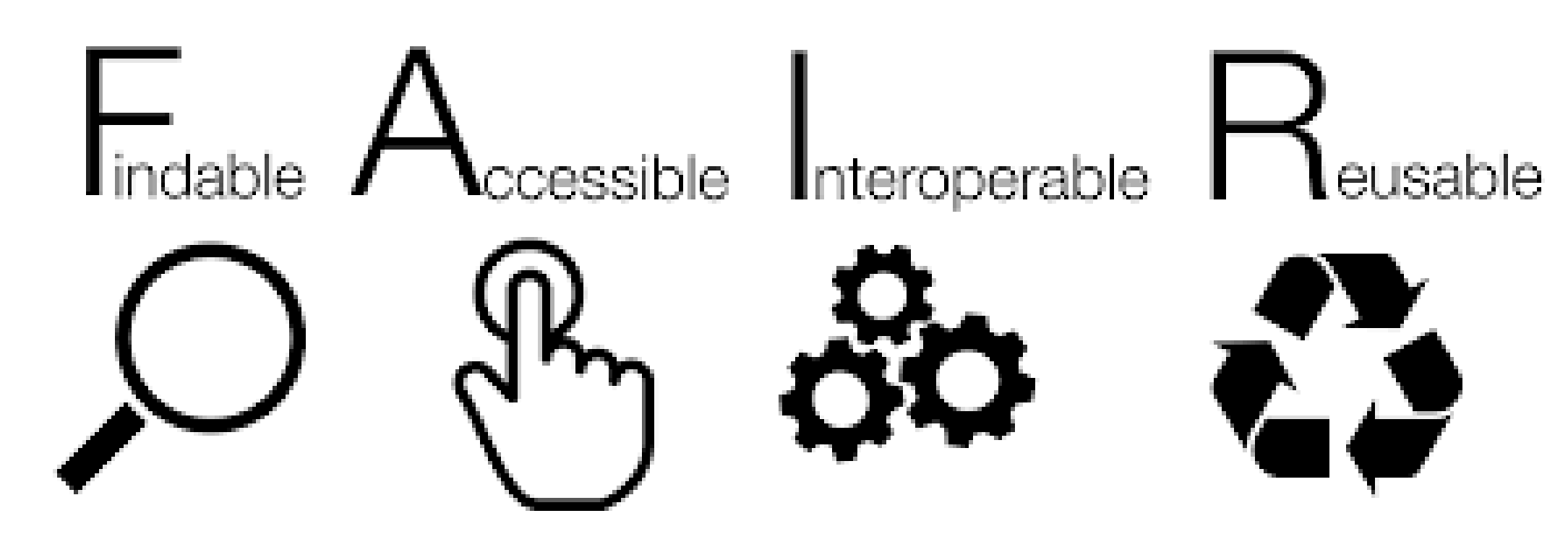

Findable: sufficiently rich metadata and unique persistent identifier Accessible: metadata is in machine and human readable format Software and metadata is deposited in trusted community approved repository

Interoperable: uses community accepted standards and platforms, making it possible for users to run the software Reusable: has clear license and documentation 
Examples of FAIR in weather \& climate research

Examples of FAIR in weather \& climate research 


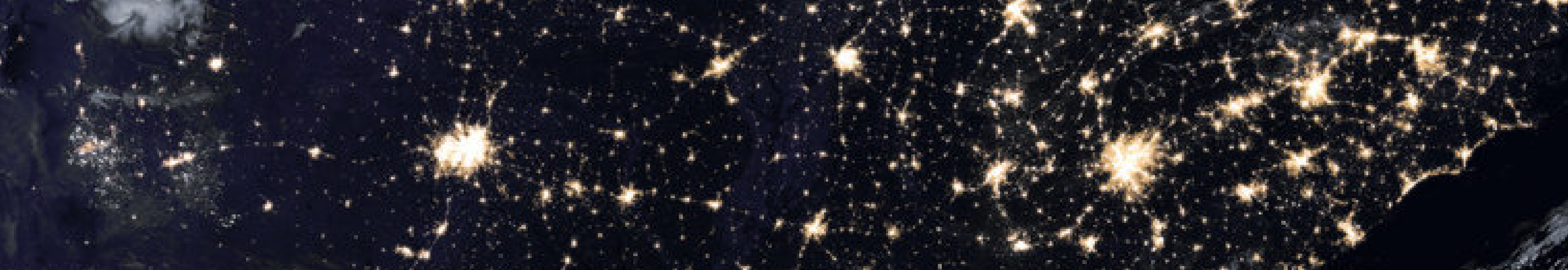




\section{Findable open data in climate research}

Hosted by Department of Energy

Lawrence Livermore National Laboratory

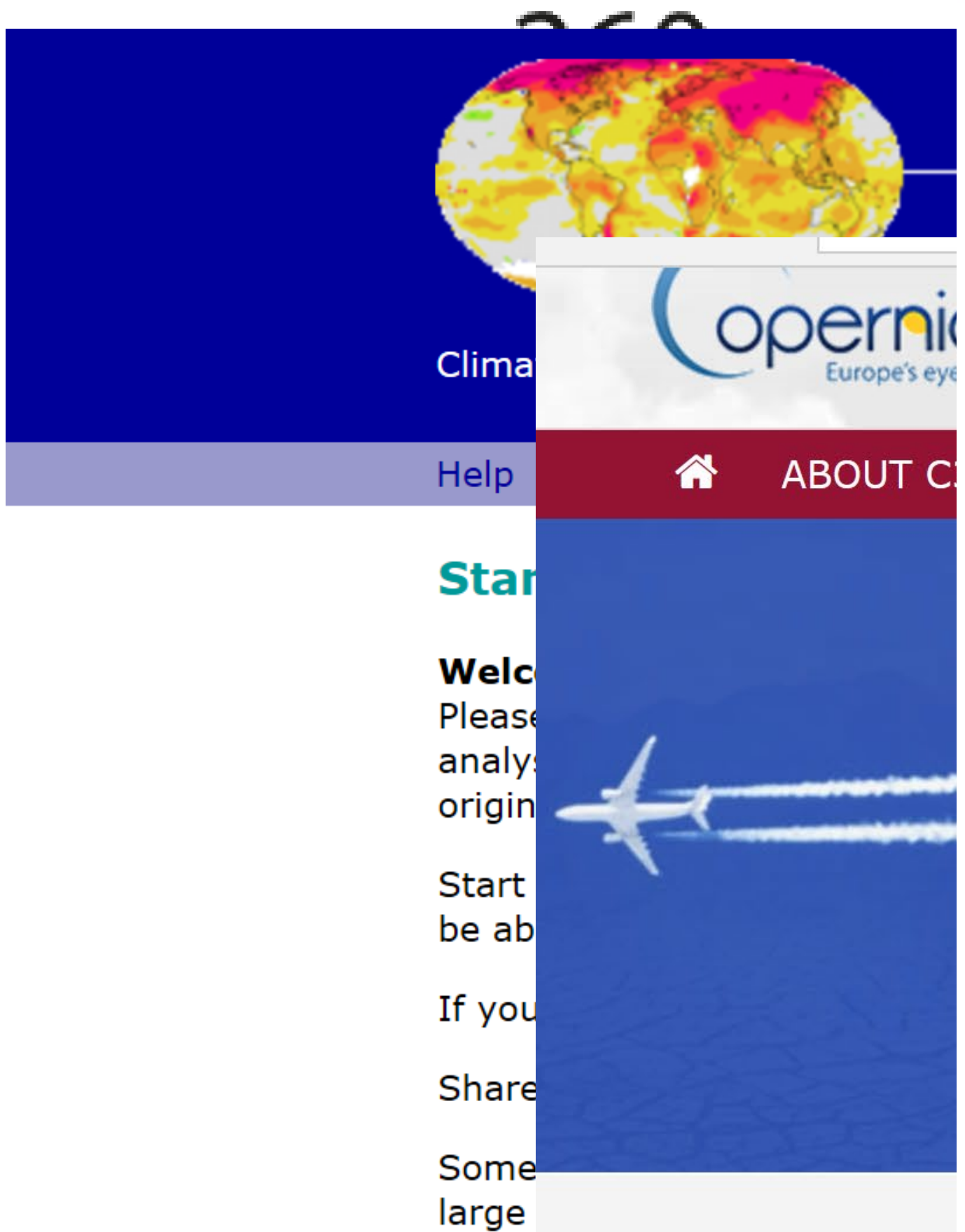

WCRP COMIP5

World Climate Research Programme

Home About Us Contact Us

Coupled Model Intercomparison Project 5 (CMIP5)

Search \& Download Data ?

Simple Text Search

Go Q More sea

IN FOCUS

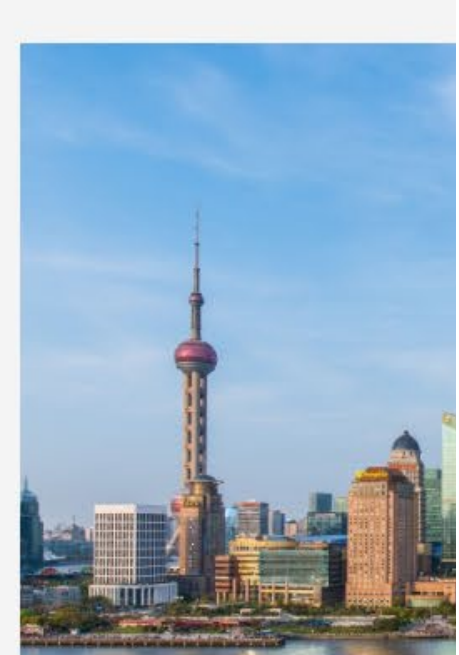

PCMDI

Program for Climate Model

Diagnosis and Intercomparison

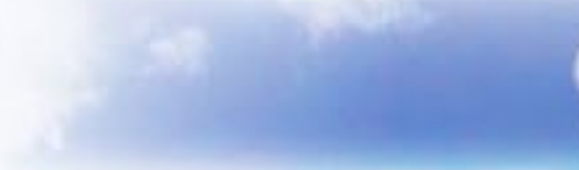

Search for CMIP5 project data

Data Search Tip: use the "Show all Replicas" checkbox to expand the data search to additional models.

To enable CMIP5 data download, you need to register for a CMIP5 access group based on your use of the data:

C3S at the ICE

17 May 2018

CMIP5 Research CMIP5 Commercial 


\section{Interoperable in climate research}

- Netcdf : is a set of software libraries and self-describing, machine -independent data formats that support the creation, access, and sharing of array -oriented scientific data.

- Climate and Forecasting conventions

- CMOR: climate model output writer

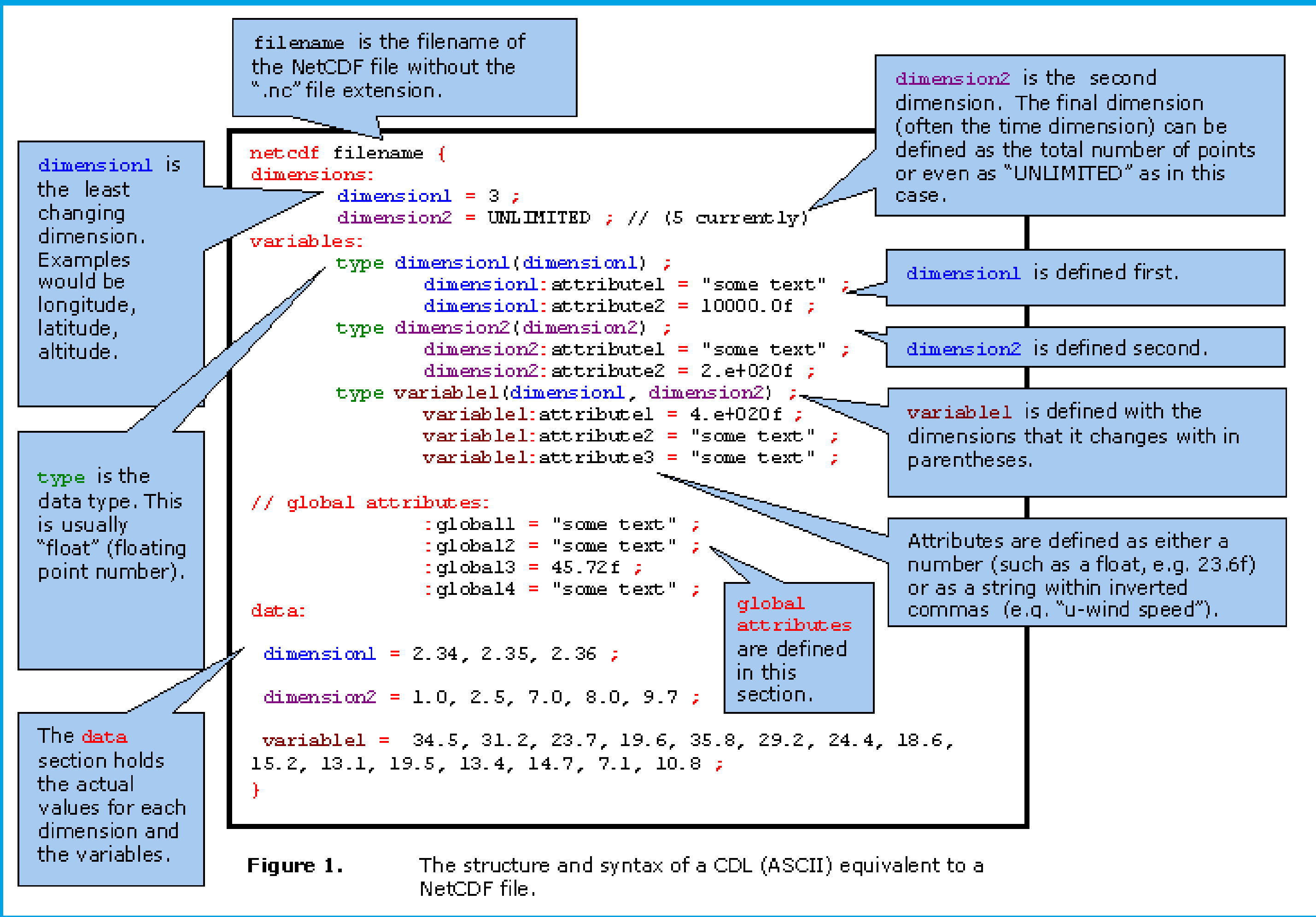



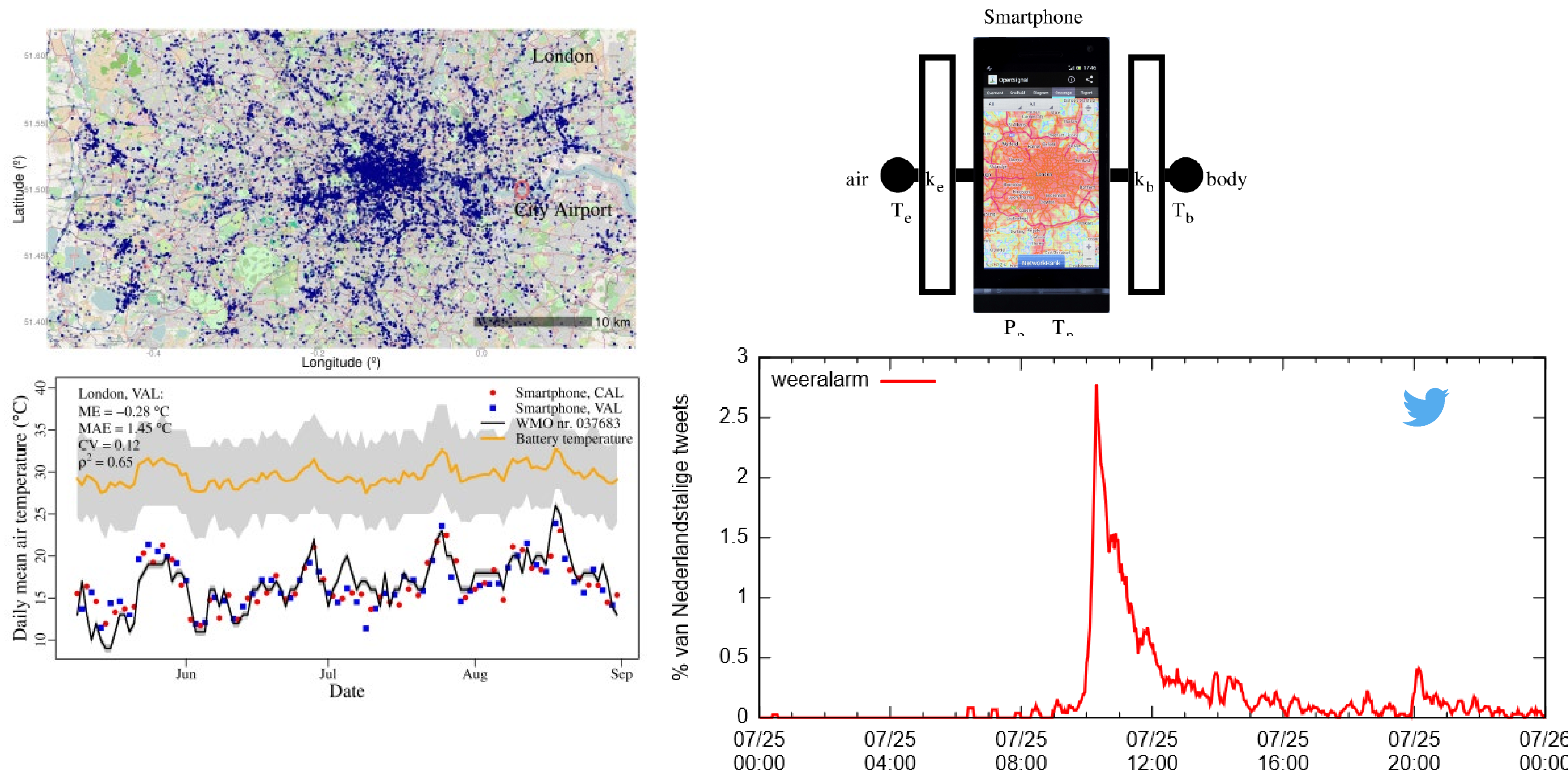

Overeem et al GRL 2013

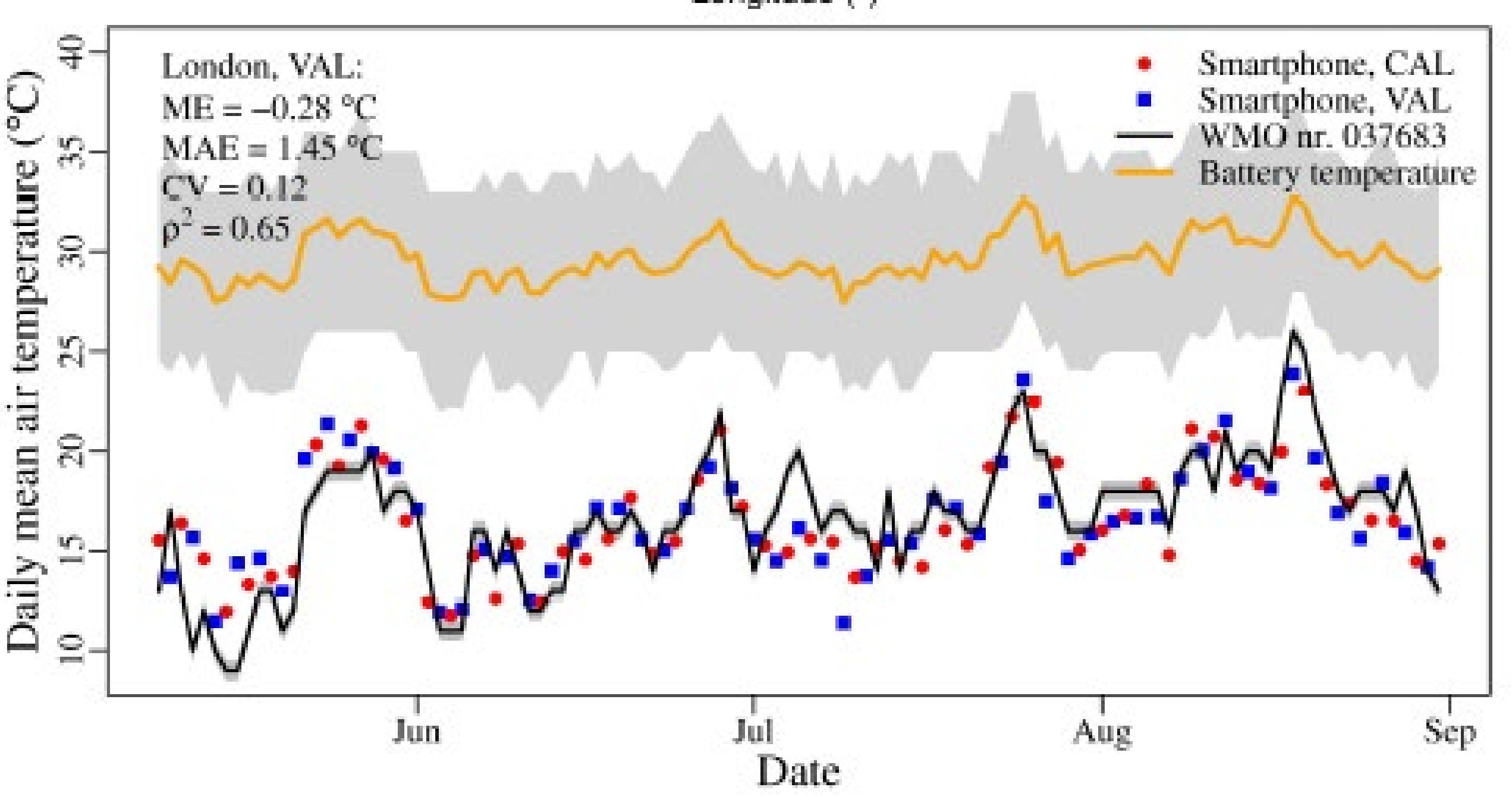

00:00

08:00

20:00

$07 / 26$
$00: 00$ 


\section{Downscaling}

Daily forecasts

WRF3.5 + urban module (SLUCM)

48 hour runs, 24 hour spin-up

Domain 1: $12.5 \mathrm{~km}$

default setup

Domain 2: $2.5 \mathrm{~km}$

default setup

Domain 3: $500 \mathrm{~m}$

hi-res landuse,

Rijkswaterstaat river temperatures

Domain 4: 100m

Rijkswaterstaat river temperatures, TOP10NL, satellite imagery, AHN2 (height map), CBS data

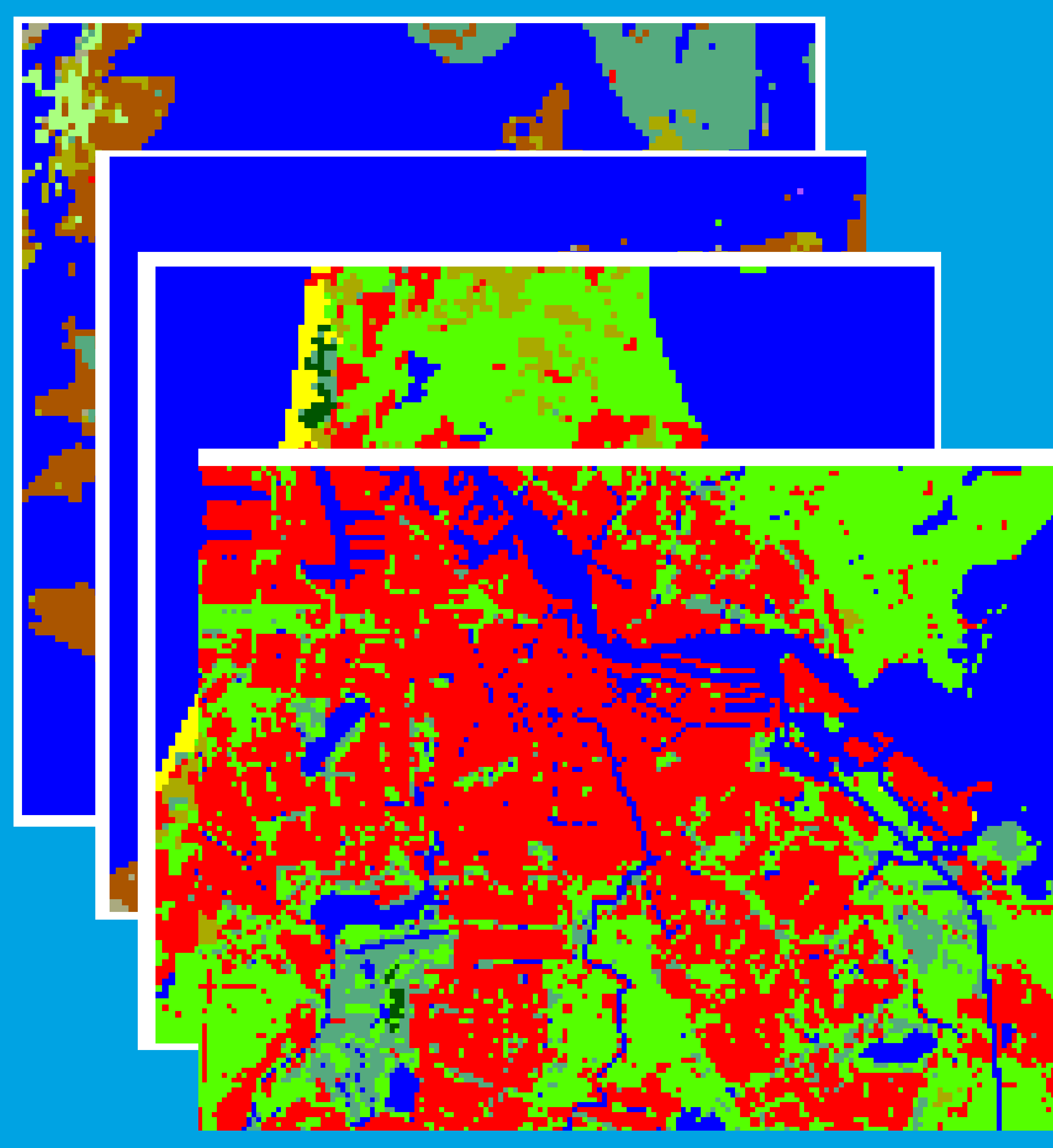



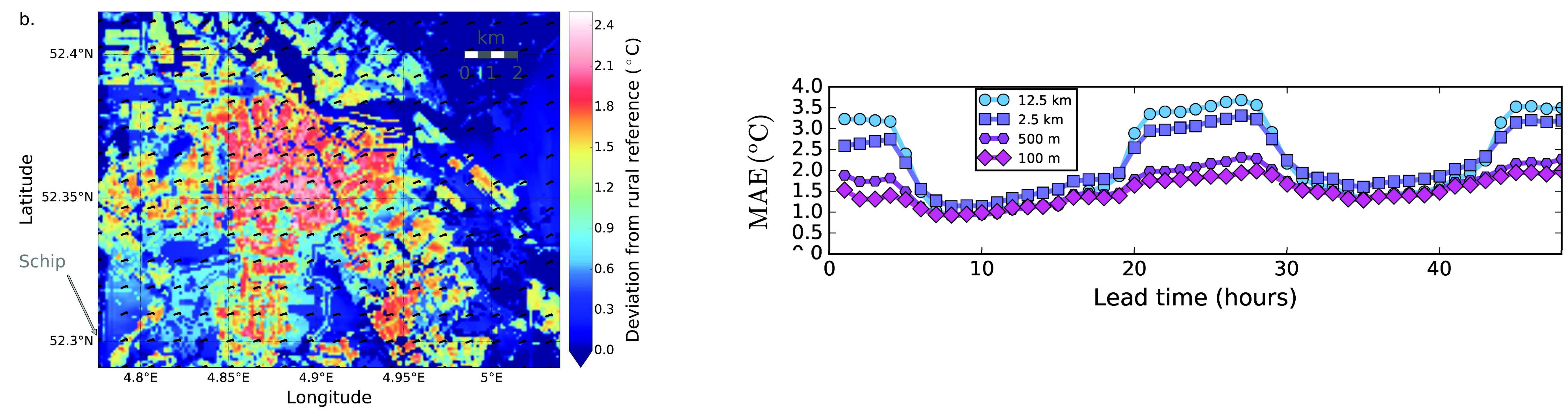
$\ldots$

[ ]: from ewatercycle.models import PcrGlobWB

from ewatercycle. forcings import Gfs

from ewatercycle.plotting import geo plot, timeseries plot

[ ]: parameterset $=$ PcrGlobWB. parametersets[ "RhineMeuse30min"]

\# or generate a parameterset for a region

parameterset = PcrGlobWB. parameterset_from_region (latmin=4, latmax=10, lonmin=45, lonmax=55)

[ ]: forcing $=\mathrm{Gfs}($ )

[ ]: start = ' 1999-01-01T00:00:00Z"

end $=" 2010-31-12 \mathrm{~T} 23: 59: 59 \mathrm{Z}$

[ ]: model = PcrGlobWB (parameterset=parameterset,

forcing=forcing,

start=start,

end=end

)

[ ]: discharge over time $=[$ ]

while model.current time < model. end time:

model . update()

discharge_over_time.append (model.discharge)

[ ]: \# Plot discharge of last time step

geo_plot (model.discharge)

Niels Drost, pers. Comm, NLeSC/TUD/UU/WUR/Deltares eWatercycle II project 
Still...far from actionable information for decision making

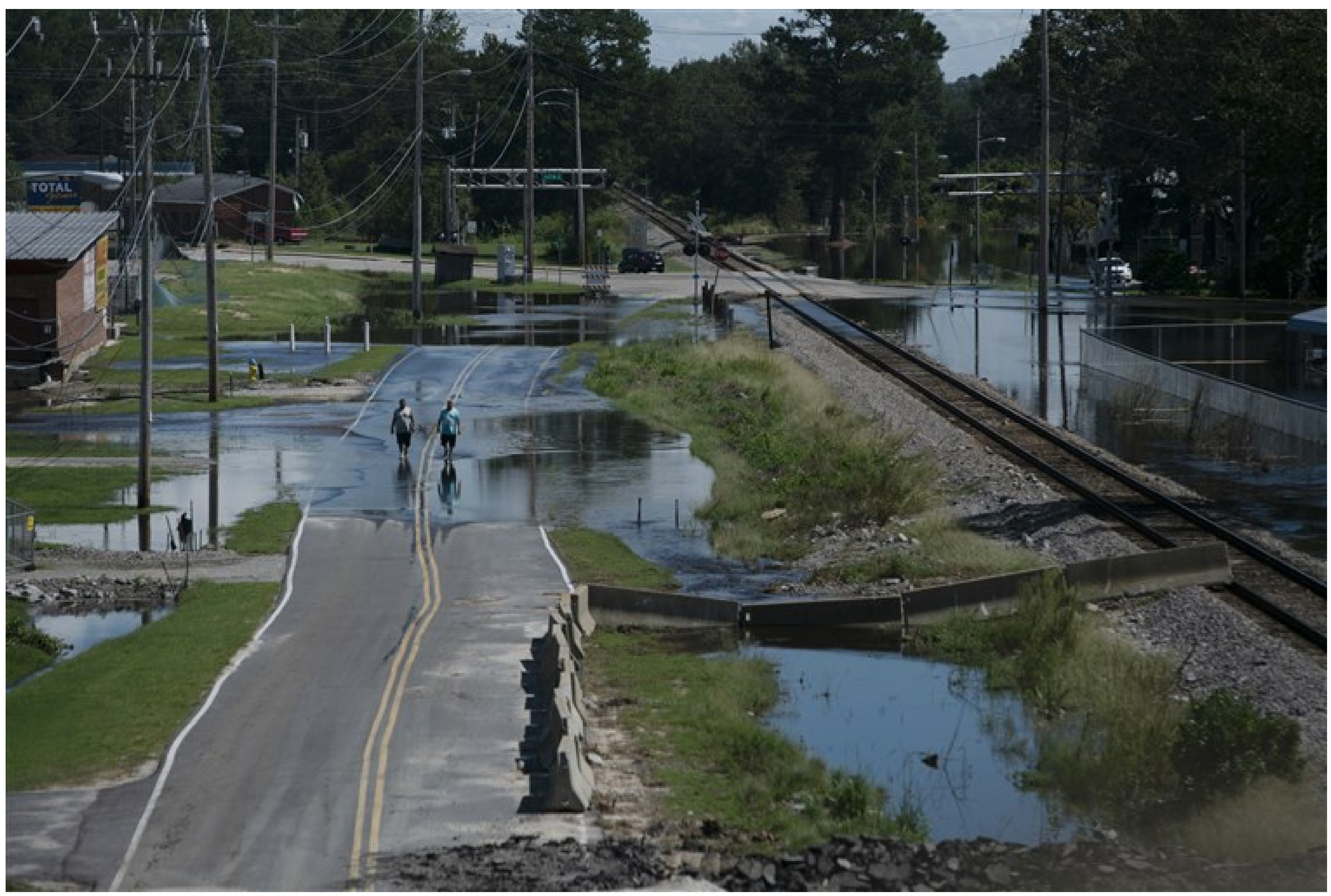




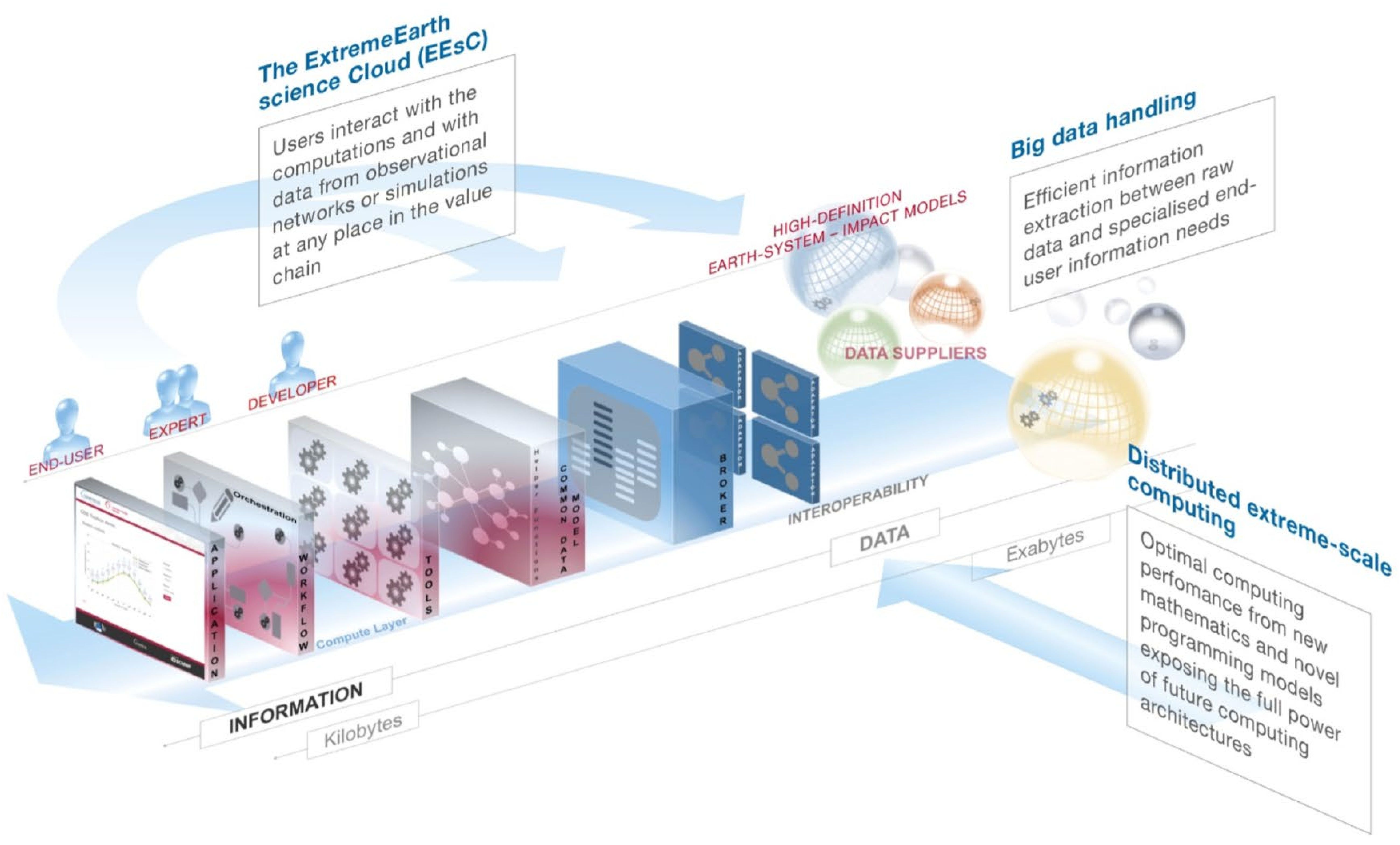




\section{Examples of FAIR in life sciences \\ Exampies ort

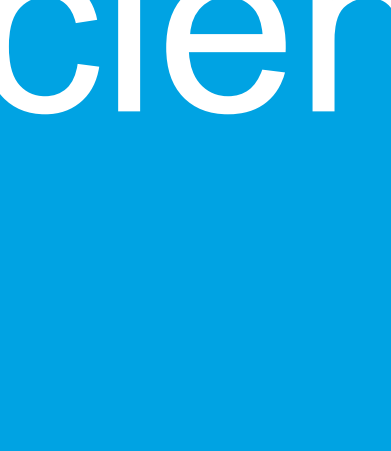

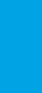

(1)

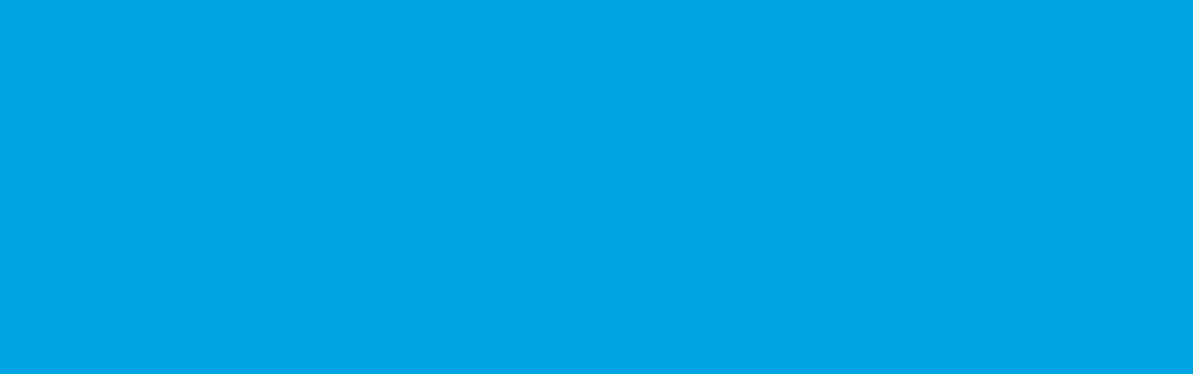

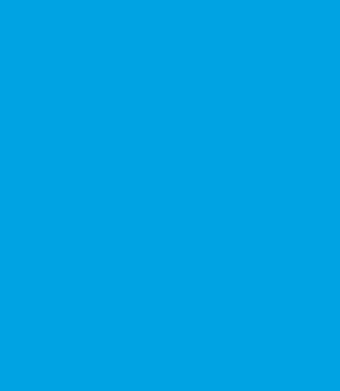

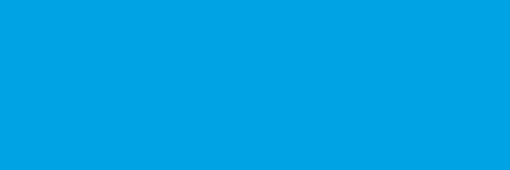

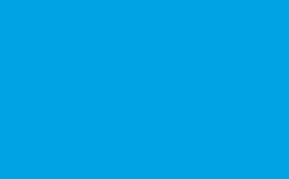

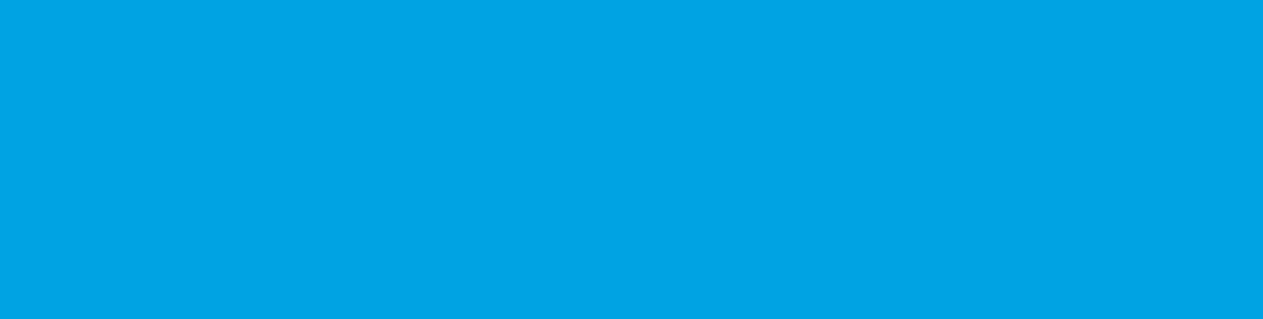

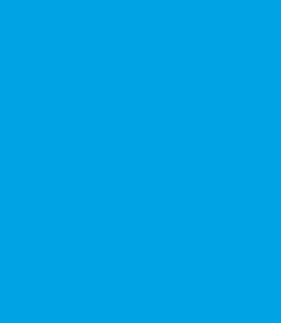

(

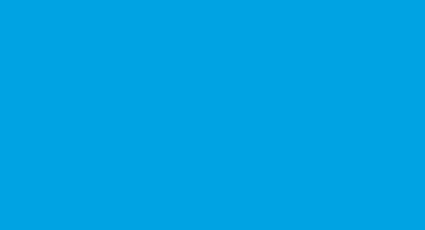

(

列

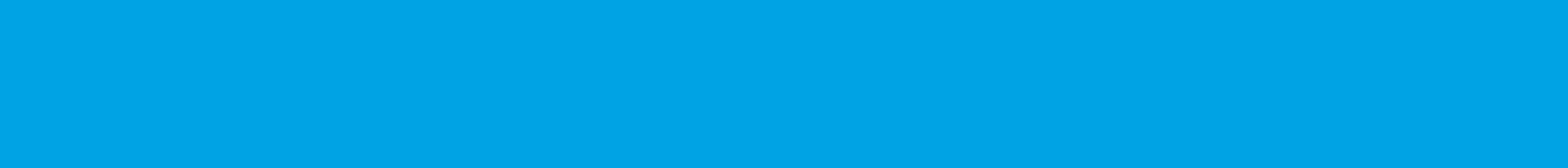




\section{Big data landscape in}

\section{health care}

- Clinical research

- $3 \%$ of patients

- $100 \%$ of features

- $5 \%$ missing

- 285 data points

- Clinical registries

- $100 \%$ of patients

- $3 \%$ of features

- $20 \%$ missing

- 240 data points

- Clinical routine

- $100 \%$ of patients

- $100 \%$ of features

- $80 \%$ missing

- 2000 data points 


\section{A Global Distributed Routine Data Registry}

- Keep data locally

- Standardize it according to an ontology

- Make and send around learning and quality indicators

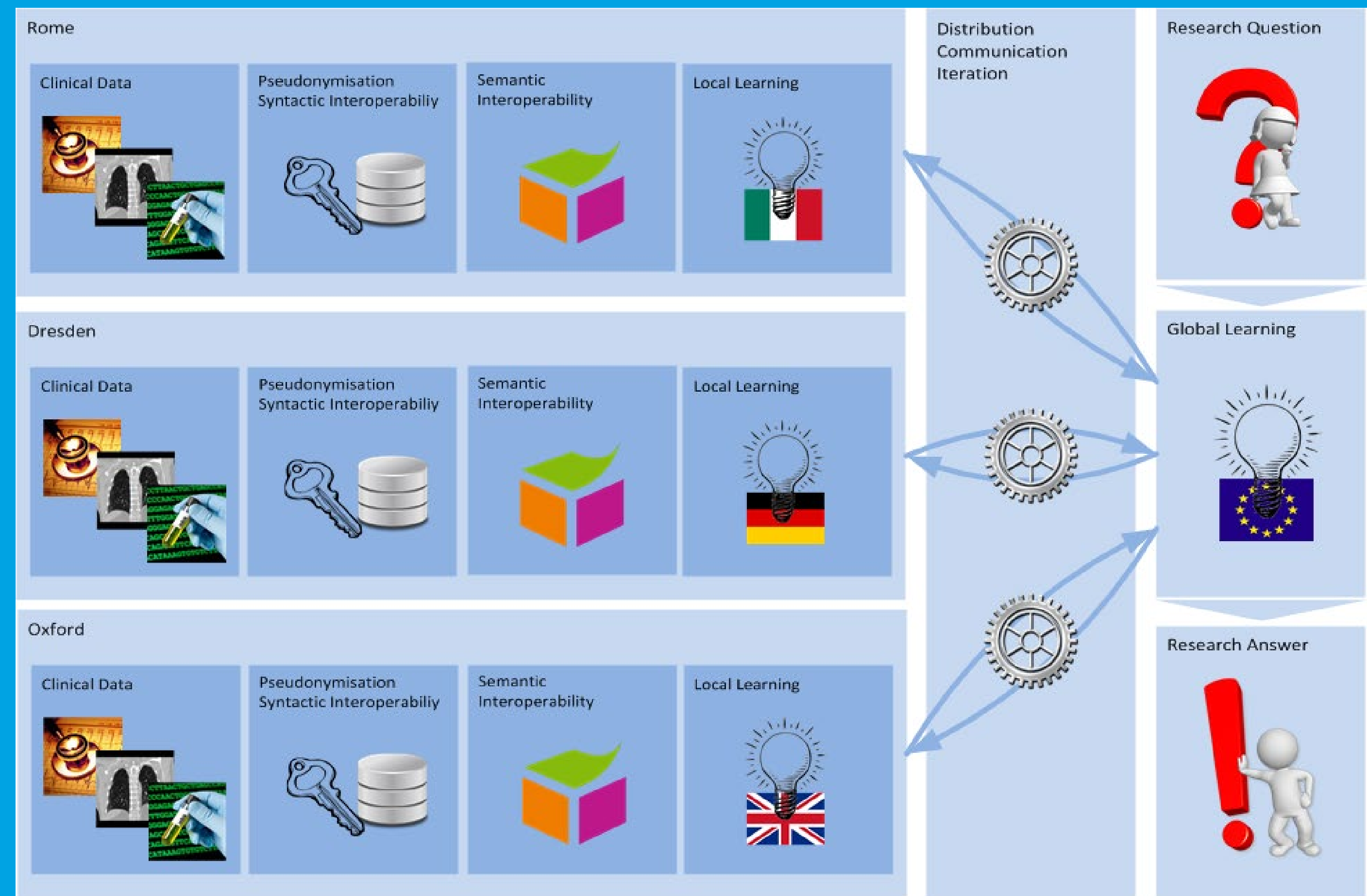

- Share the results \& quality indicators

- not the data!! 


\section{Reproducible science}

Requires not only data to be FAIR but also

Software:

- Research Software Directory $(F+A)$

- Use standard file formats, Docker, API's, etc. (I)

- NLeSC guide: https://guide.esciencecenter.nl/

(R) Workflows:

- Common Workflow Language

- platform independent workflow definition and execution

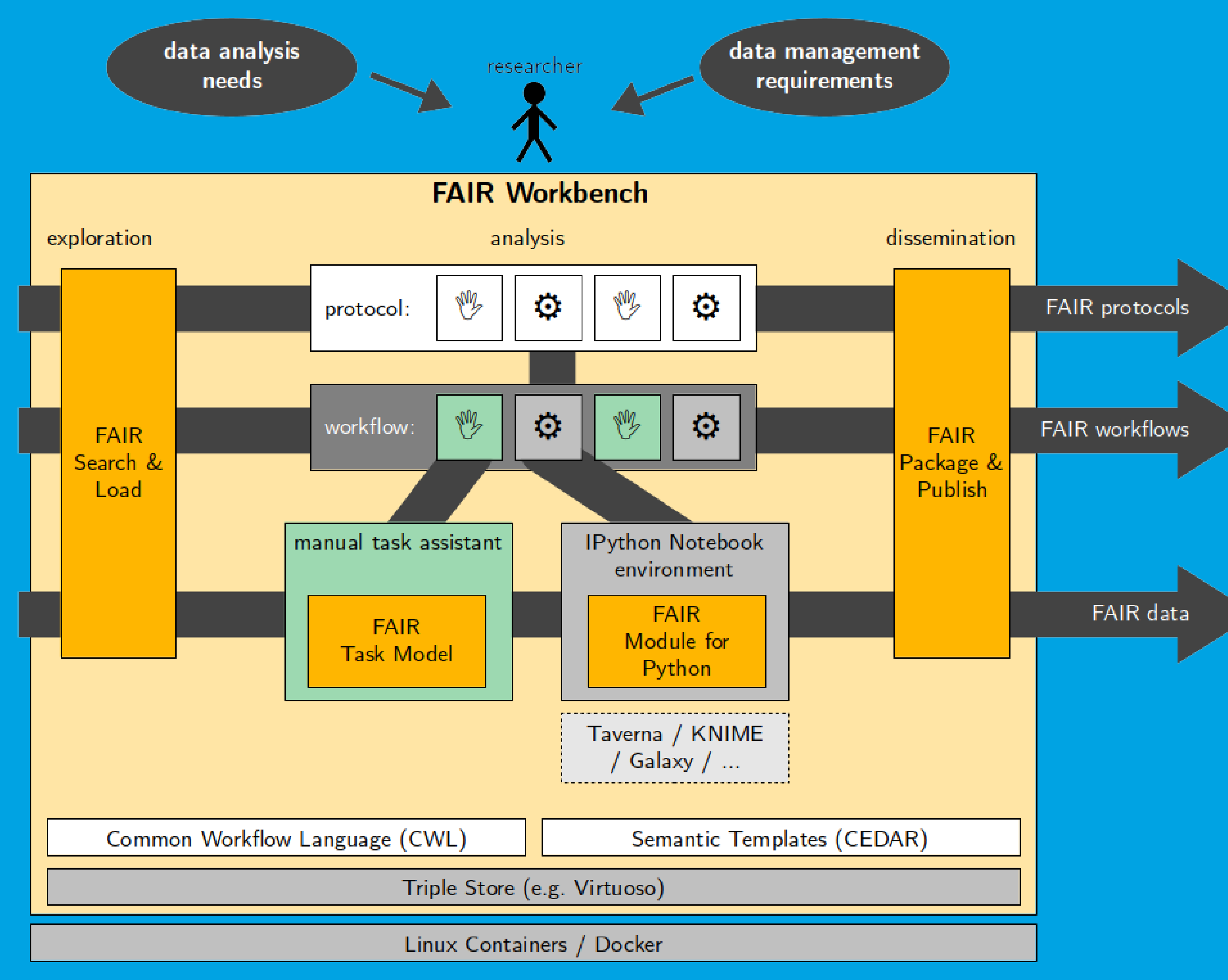

FAIR Workflows project Collaboration with Tobias Kuhn, Michel Dumontier 


\section{Trait (e.g. color)}
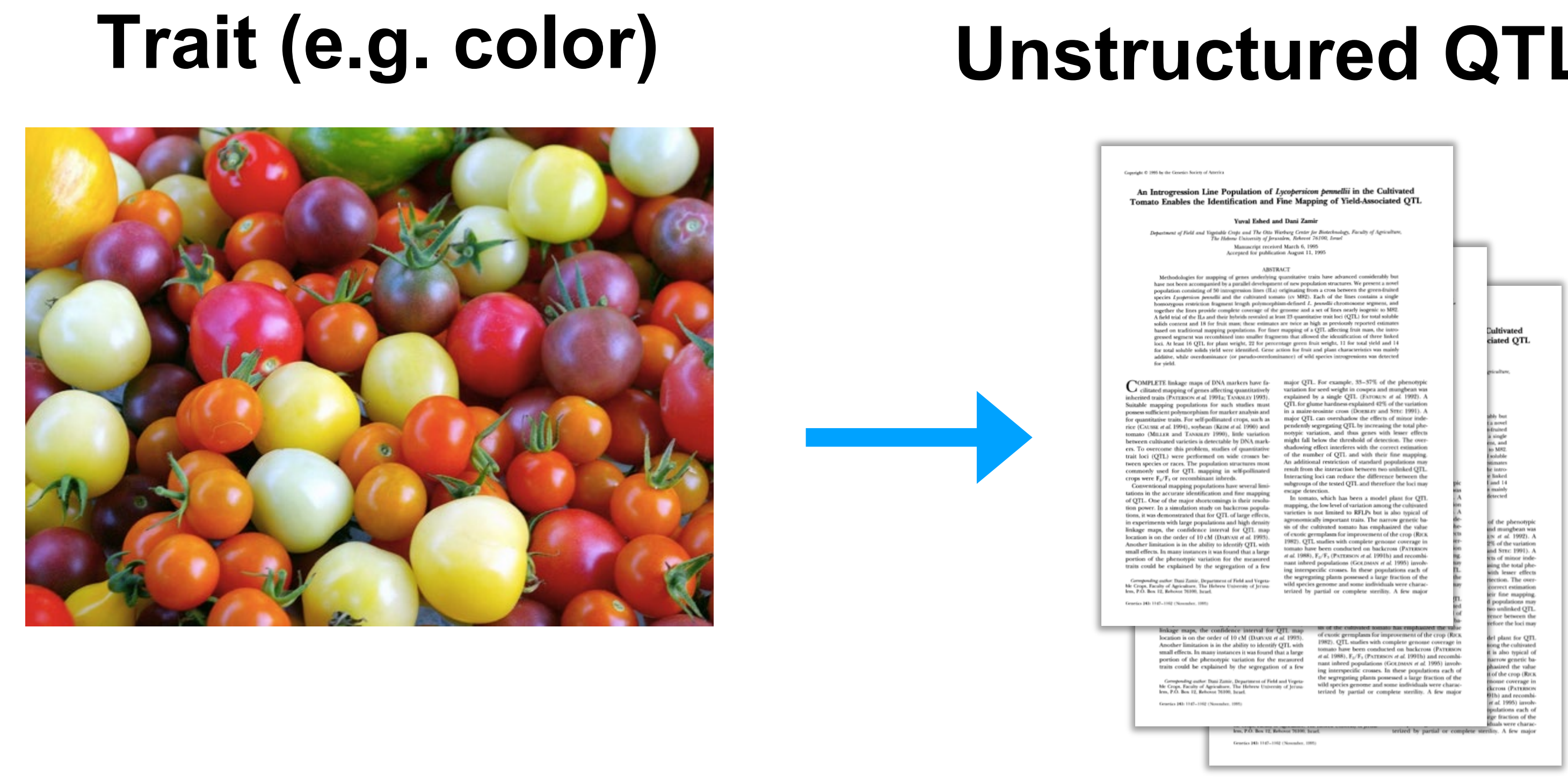

\section{FAIR data}
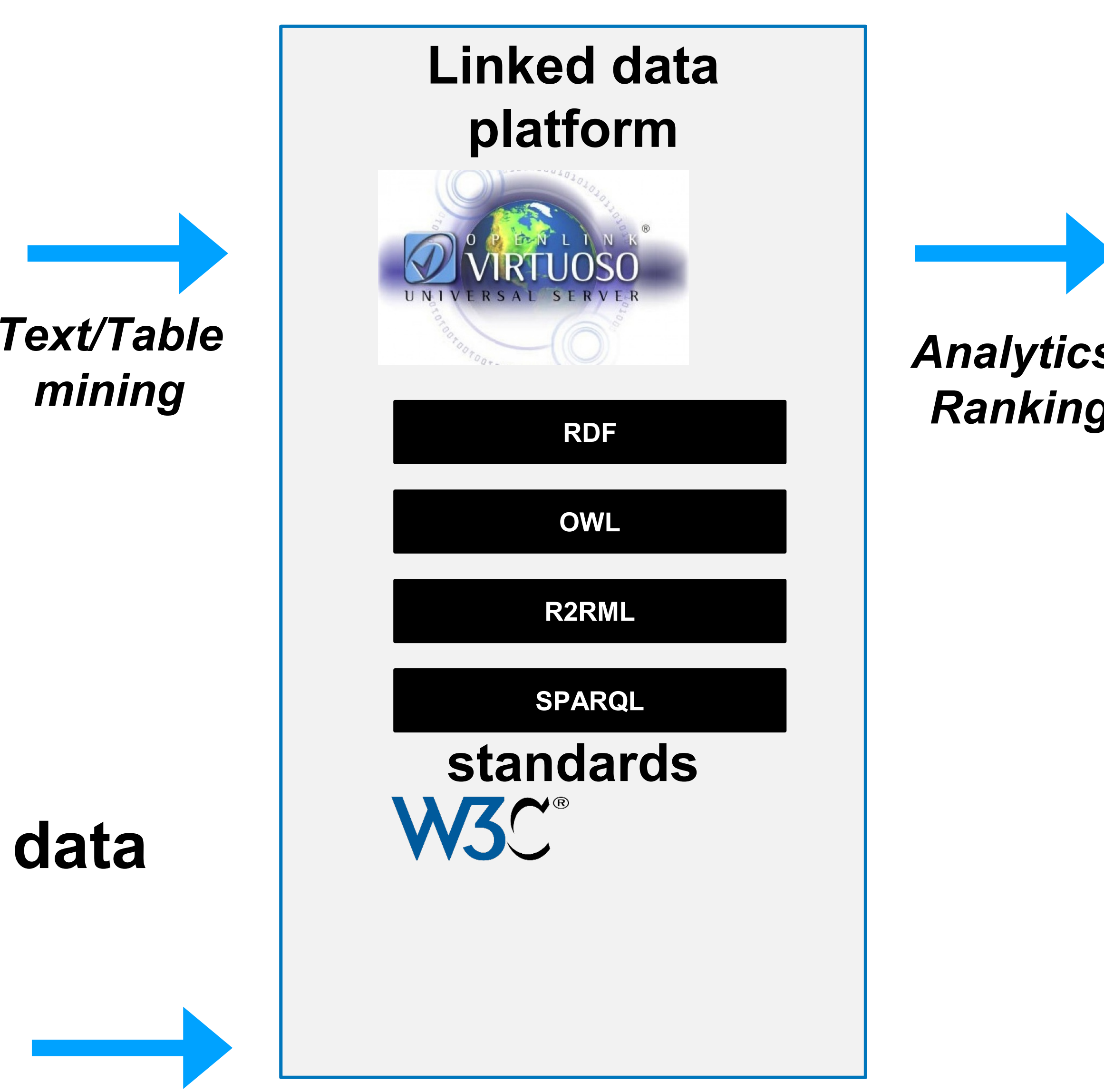

Analytics/

Ranking

Candidate genes for traits
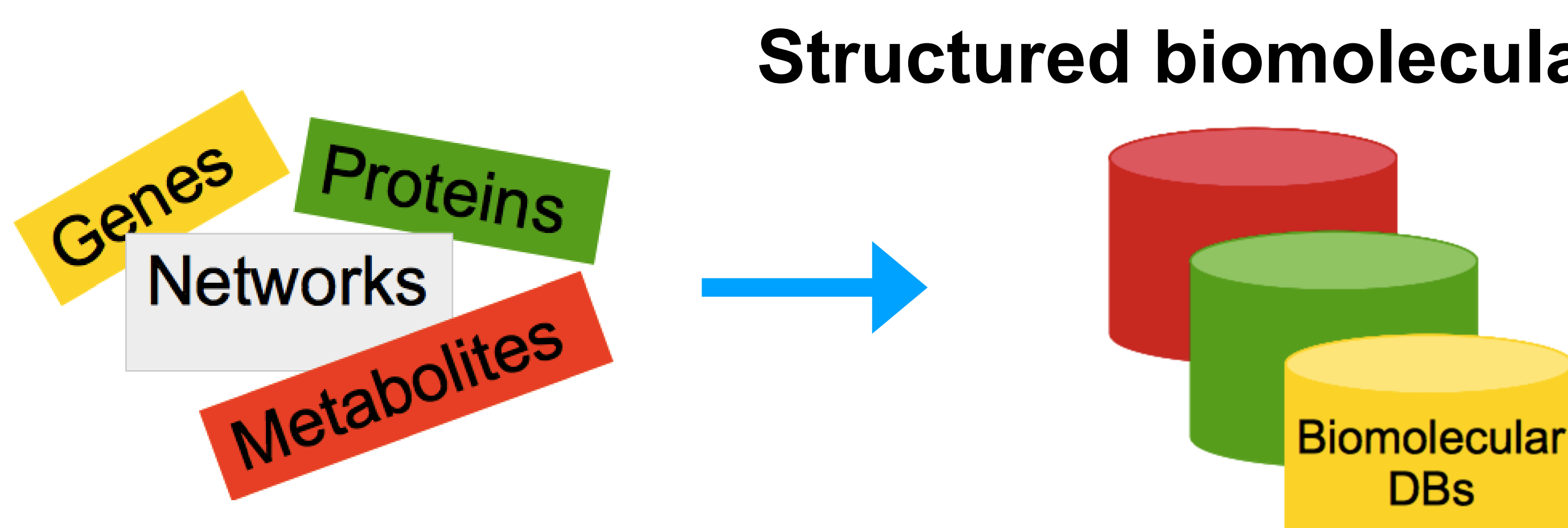

Genome

annotations

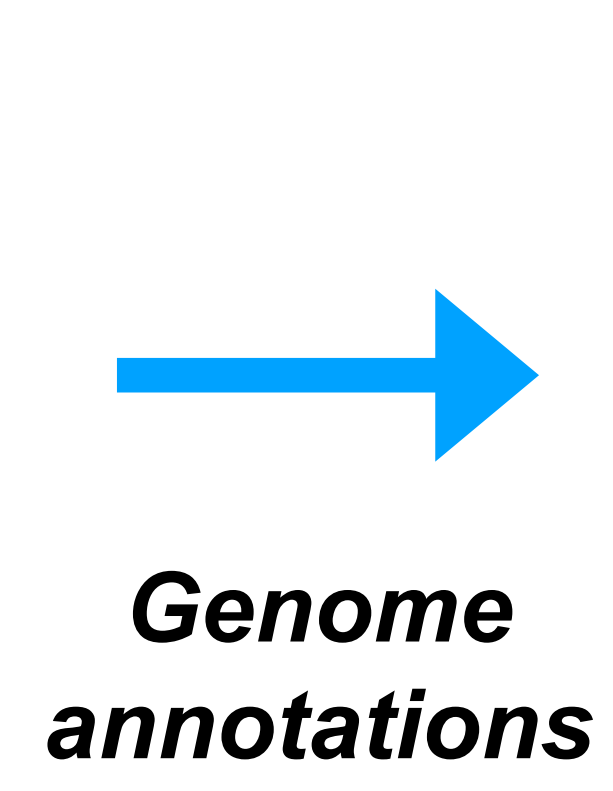

Session F: Arnold Kuzniar, Richard Finkers, Richard Visser 
Microbiome (e.g. in the human gut)

Metabolomes (Natural products)
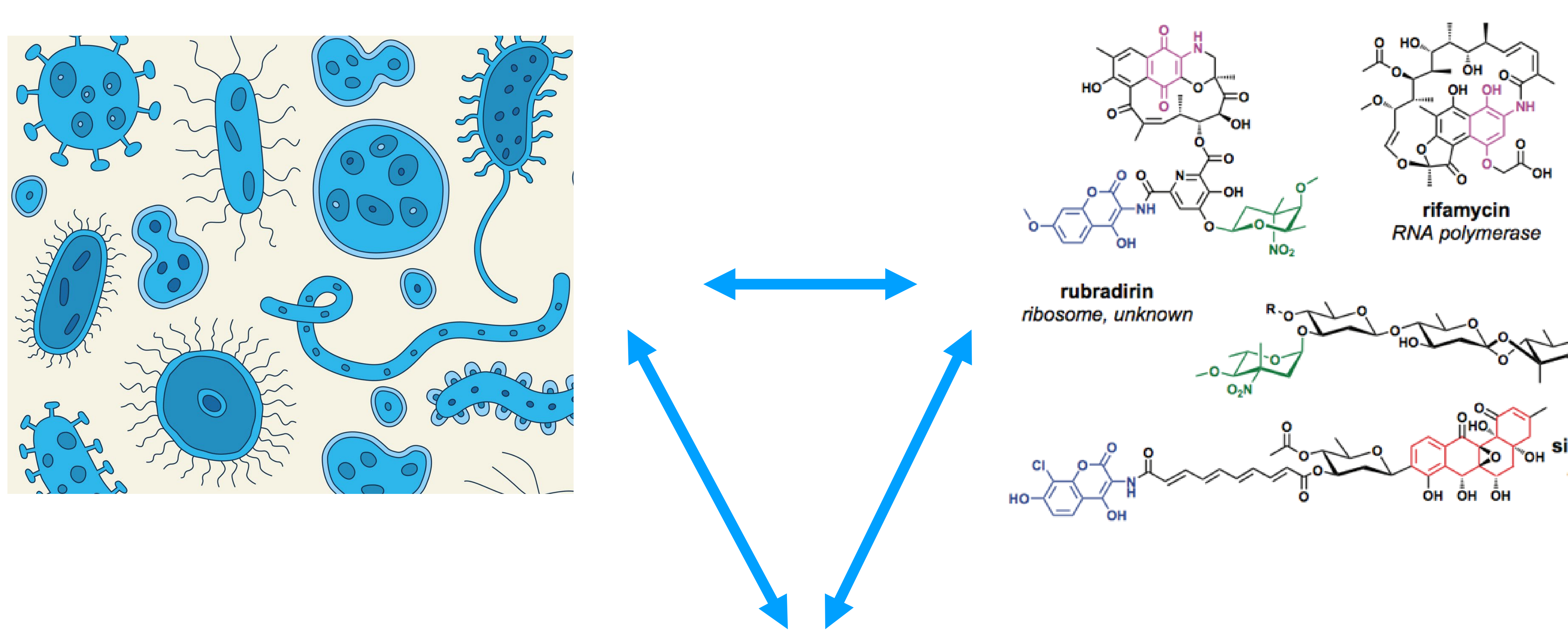

rubradirin ribosome, unknown
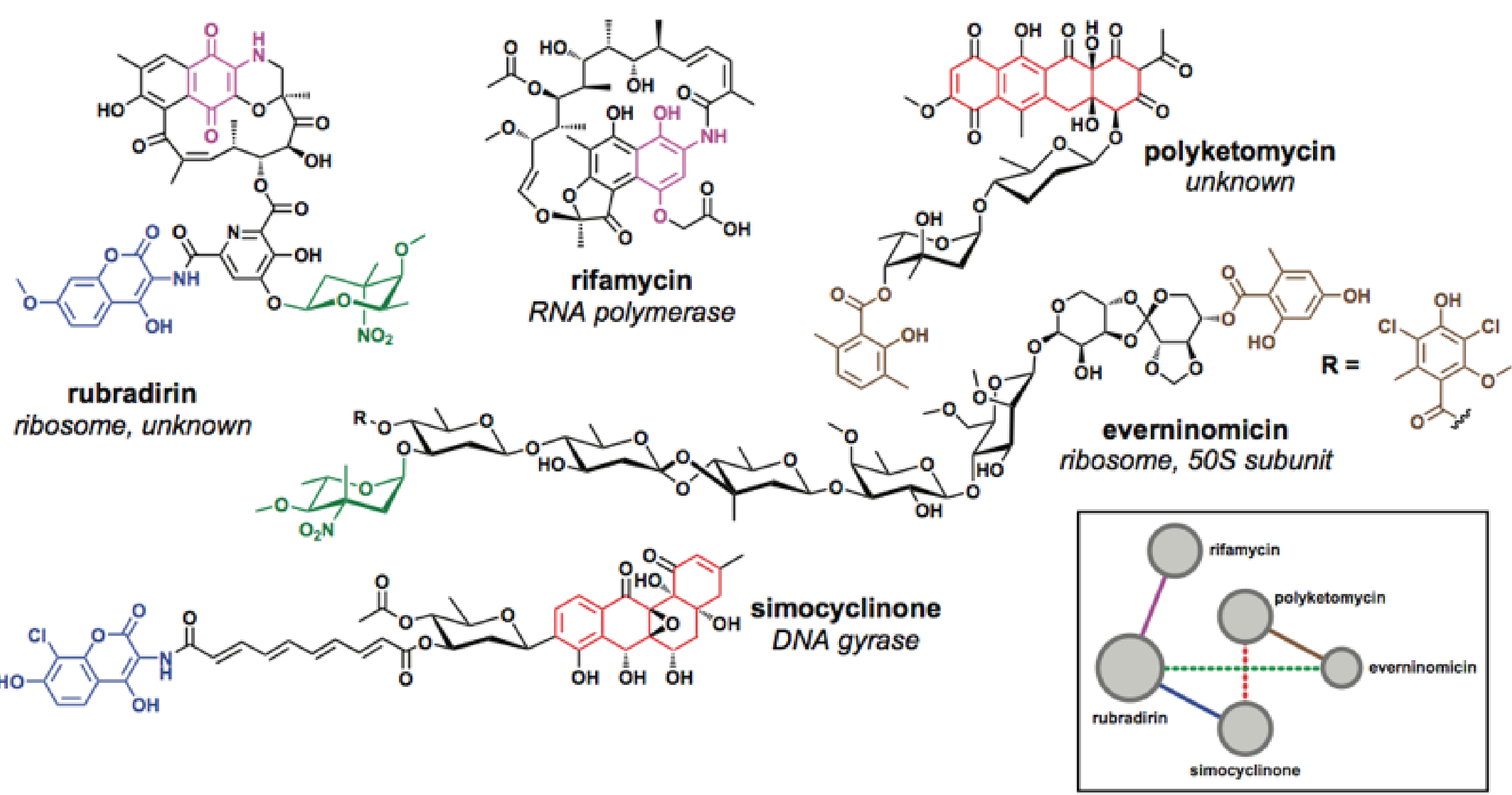

\section{Genomes (Biosynthetic gene clusters)}

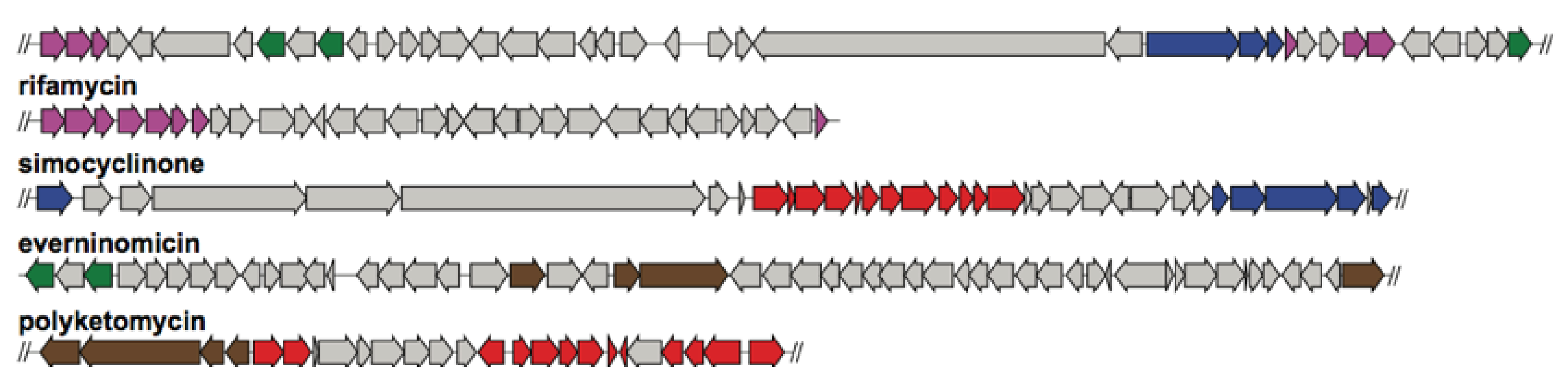

Session F: iOMEGA project Justin van der Hooft, M. Medema S. Verhoeven, F. Huber, L. Ridder 
FAIR: Just do it!

- Supports working across domains of research

- Requires domain knowledge, digital competences \& digital infrastructures, hence an collaborative work environment!

- Absolutely necessary for evidence - based (and transparent) decision making

- Not only data, but also software, worfklows, methods.. 


\section{Thank you$$
\text { Thank you }
$$

thank you

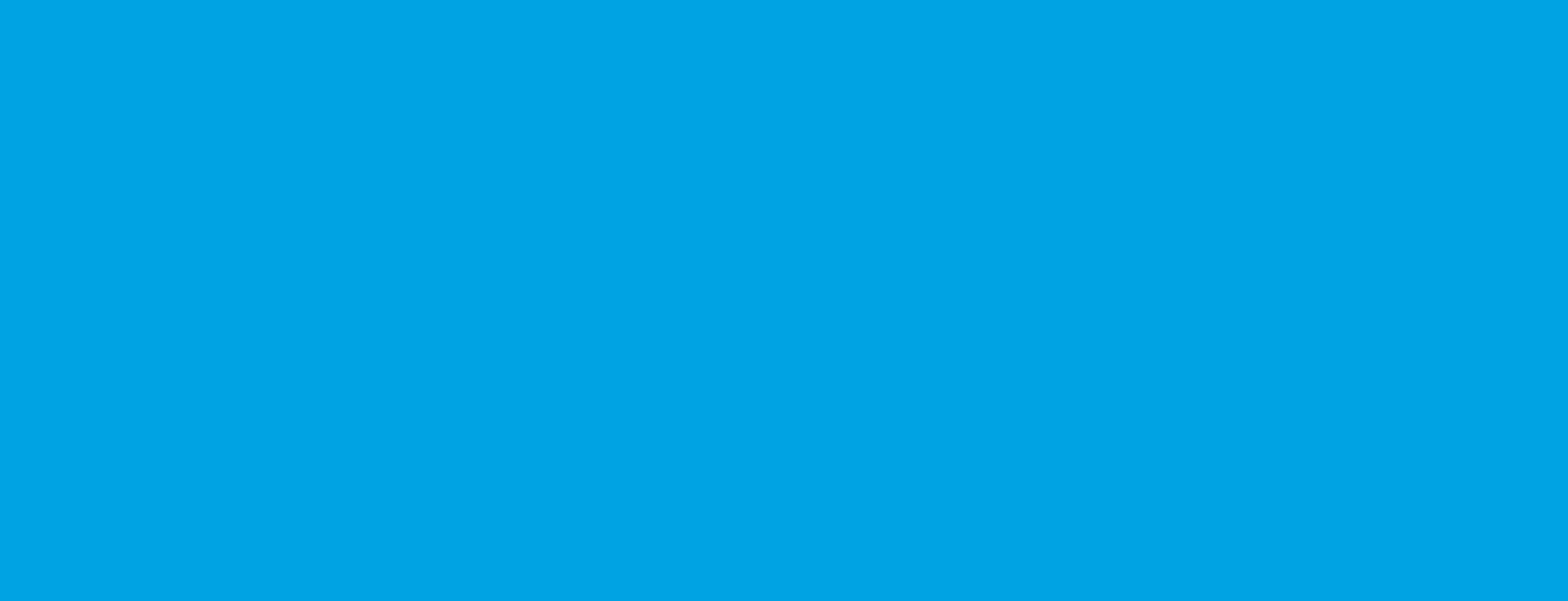

